\title{
Discos em construção - etnografia dentro de estúdios
}

L Paulo Menotti Del Picchia

Universidade de Sáo Paulo, Sáo Paulo, Sáo Paulo, Brasil

DOI: 10.11606/issn.2316-9133.v24i24p117-139

resumo Neste artigo, apresento uma etnografia musical de processos de produção de discos dentro de estúdios paulistanos, descrevendo e discutindo as práticas criativas observadas. Entre 2011 e 2013, pude acompanhar de perto os trabalhos de três artistas ativos na cena musical paulistana contemporânea: Tatá Aeroplano, Rodrigo Campos e Kiko Dinucci. Trago aqui as experiências etnográficas do disco Tatá Aeroplano e do disco Metal-Metal. Procurei delimitar os aspectos mais significativos que caracterizam o fazer musical desse grupo sonoro, fornecendo indícios para uma reconfiguração do disco como objeto artístico no cenário musical contemporâneo. $\mathrm{O}$ disco emerge como agente social que transforma a vida dos artistas.

palavras-chave Etnografia; Música; Disco; Artista; Agente.

\section{Albums under construction - ethnographies within studios}

abstract In this article, I present a musical ethnography of record production processes in three studios in São Paulo, describing and discussing the creative practices observed. I was able to closely follow the work of three artists active in contemporary São Paulo’s music scene: Tatá Aeroplano, Rodrigo Campos and Kiko Dinucci. I bring here the ethnography experiences of the albuns Tatá Aeroplano and Metal-Metal. I tried to delimit the most significant aspects that characterize the music making of that sound group, providing evidence for a reconfiguration of the record as an art object in the contemporary music scene. The album emerges as a social agent that transforms the lives of artists.

key words: Ethnography; Music; Album; Artist; Agent. 


\section{Introdução: antropologia, música e estúdios}

A antropologia da música é a área de estudos que procura descrever o universo sonoro humano ao abordar sons, instrumentos, melodias e harmonias (o que seria usual num estudo musicológico). Entretanto, também procura falar de parentesco, rituais, cosmologia, política, entre outras coisas (a parte propriamente antropológica da área). Uma boa pesquisa etnomusicológica conectaria, em sua narrativa dos fazeres musicais de um grupo, elementos aparentemente não musicais. ${ }^{1}$

A etnografia da música é o escrito sobre as maneiras que as pessoas fazem música. Ela deve estar ligada à transcriçáo analítica dos eventos, mais do que simplesmente à transcrição dos sons. Geralmente inclui tanto descriçóes detalhadas quanto declaraçóes gerais sobre a música baseada em uma experiência pessoal ou um trabalho de campo. (SEEGER, 2008, p. 239)

Boa parte do que constitui o campo de estudos da antropologia da música lida com percepçóes e discursos humanos sobre o material sonoro. Como Seeger acabou de afirmar acima, ela está ligada às maneiras como as pessoas fazem músicas. Essa perspectiva é importante para esta pesquisa, mas se mostrou limitada. Proponho também explorar como as pessoas são feitas pela música e, em nosso caso específico, como os artistas também são feitos pelos discos que gravam.

Isso implica reconhecer também as agências não humanas do fazer musical. Reconhecer que a antropologia talvez seja o espaço privilegiado para conectar numa mesma narrativa seres humanos, instrumentos, estúdios, microfones, crenças, relaçóes familiares, discos, computadores, leis de incentivo à cultura, crise na indústria fonográfica, notícias de jornal - todos basicamente com o mesmo estatuto ontológico. Essa simetrização de posiçôes foi algo que a antropologia da música ainda não deu conta de realizar de forma satisfatória. Busquei então auxílio em textos de Bruno Latour, para quem a antropologia seria a forma de se conectar numa mesma descrição as naturezas-culturas. Numa mesma análise, fatos reais, sociais e discursivos aparecem juntos para explicar um povo ou um grupo.

Porque o buraco de ozônio é por demais social e por demais narrado para ser realmente natural; as estratégias das firmas e dos chefes de Estado, demasiado cheias de reações químicas para serem reduzidas ao poder e ao interesse; o discurso da ecosfera, por demais real e social para ser reduzido a efeitos de 
sentido. Será nossa culpa se as redes são ao mesmo tempo reais como a natureza, narradas como o discurso, coletivas como a sociedade? (LATOUR, 2009, p. 12)

Este artigo se inspira em Latour para analisar fazeres musicais urbanos contemporâneos, conectando numa mesma narrativa as agências humanas e não humanas dos processos observados. Inspiramo-nos também em Alfred Gell, ao entender a agência da música e dos discos a partir de noção desenvolvida no livro Art and Agency (1998). Agência, nesse texto, aparece como aquilo que causa eventos. A especificidade do olhar antropológico estaria em, justamente, entender como as obras de arte agem socialmente. É nesse sentido que ele propõe uma análise dos objetos artísticos em termos de agência, se diferenciando dos estudiosos que tratam a arte em termos estéticos. Em nosso caso, entender a música como manifestação artística que age me levou a tratar o disco como um objeto-sujeito musical.

Durante a pesquisa, acompanhei três compositores - Tatá Aeroplano, Kiko Dinucci e Rodrigo Campos ${ }^{2}$ e suas respectivas bandas. Eles são representantes de um grupo sonoro - que "é um grupo de pessoas que compartilha uma linguagem comum, junto com ideias comuns sobre a música e seus usos" (BLACKING, 2007, p. 208) - mais amplo, formado por um grande número de pessoas que compartilham o fato de lançarem discos autorais nos mais variados suportes e formatos, sem estarem necessariamente vinculadas a uma grande gravadora. Serão exploradas aqui as maneiras pelas quais um determinado grupo sonoro vem fazendo música na cidade de São Paulo, sendo que a gravação de discos se apresenta como o principal ponto que liga os membros desse grupo. Escrevo também sobre como esses discos fazem esses artistas num processo de mão dupla. Como os equipamentos dentro do estúdio de gravação moldam novas formas de se fazer e pensar a música.

Os estúdios são elementos fundamentais no fazer musical urbano contemporâneo. Para Latour (2000), é na observação das práticas sociais dentro de laboratórios que está a possibilidade real de se realizar uma etnografia da ciência, revelando a ciência em construção e não a ciência pronta e acabada, lacrada em caixas de pandora inacessíveis aos leigos. Ouso afirmar que é dentro dos estúdios que podemos observar os discos em construção, não como dispositivos fechados e prontos, mas como processos associativos entre humanos e não humanos, músicos e computadores, técnicos de mixagem e microfones. O estúdio é o recinto dentro do qual os sons são manipulados. Ele cria um "dentro" e um "fora" a partir da manipulação sonora. Tem como uma de suas principais características físicas o isolamento acústico, além de toda uma rede de complexos equipamentos de áudio. 
Os estúdios são lugares onde humanos, com a ajuda de diversos agentes não humanos, tentam manipular e controlar o universo dos sons. Tive a oportunidade de passar por alguns dos principais estúdios de gravação da Zona Oeste de Sáo Paulo: o Minduca no Jardim Bonfiglioli, o YB na Vila Madalena e o El Rocha em Pinheiros, onde foram gravados alguns dos principais discos lançados em São Paulo, entre 2011-2013. ${ }^{3}$ Esses três estúdios, ao lado do Traquitana (no bairro do Bixiga), formam um circuito de estúdios de gravação ocupados por uma série de artistas e bandas que focam suas carreiras no lançamento de discos. O objetivo principal não era mapear esse circuito, mas ele se delineou de forma indireta, na medida em que eu seguia os discos, os artistas, os shows.

\section{Minduca - Tatá Aeroplano}

"Boca: Ah, menorizar que tu diz é torná-lo menor!

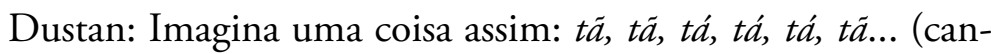
tarolando uma melodia para Bruno e Boca). Aí depois a gente arma isso benfeitinho, as notas.

(Os três tocam um pouco juntos)

Dustan (para o Bruno): Talvez seja só na cabeça mesmo. (Para o Boca) Vamos picadinho juntos, qualquer nota por enquanto. Boca: Vamos fazer o arpejo. (Ele e Dustan tocam juntos as notas nos seus instrumentos.) Seguir a linha de baixo que tu diz?! Faz tu e Bruno pra eu ouvir.

(Boca para, escuta um pouco e continua a tocar junto) Meio roquinho... Essa intro vou fazer a guitarra mais doidinha (toca frases na guitarra). Toca aí tu e Bruno que aí eu... (Dustan começa a tocar com Bruno sendo seguido em questão de segundos pela guitarra de Boca).” (Diálogo no estúdio Minduca, 05/12/2011).

O trecho reproduzido acima é a transcrição de um diálogo que aconteceu no primeiro dia de gravaçóes do disco, Tatá Aeroplano, em 5 de dezembro de 2011, no estúdio Minduca. Estávamos juntos na sala de gravação: Tatá Aeroplano, Dustan Gallas, Bruno Buarque, Junior Boca e eu. Dustan Gallas tocava seu baixo Hofner de 1972, enquanto Junior Boca tocava sua guitarra Gretsh Corvette de 1967, e Bruno Buarque sua bateria Slingerland Radio King de 1956. Os instrumentos têm nome, têm data de nascimento. Eles desenham linhas, tocam frases. Interessante notar como o discurso dos músicos humaniza seus instrumentos, por exemplo, "guitarra mais doidinha". 
Tatá ouvia atento as ideias dos músicos sobre a introdução da canção "Perigas correr" que estavam começando a arranjar. Minutos antes, todos ouviram a gravação guia que Tatá havia feito com voz e violáo em sua casa. Uma gravação guia serve de ponto de partida para uma banda ou um grupo de músicos que começam a produzir uma cançáo. Normalmente, é uma gravação somente com voz e algum instrumento de acompanhamento harmônico. Nesse caso, temos o violáo de Tatá. As estruturas das composiçóes nessas versões mais cruas normalmente são bem simples. Estão apoiadas na letra da música sem partes instrumentais, sem uma preocupação com introduções ou finais. Os outros músicos ouviram a gravação de voz e violão juntos. Dustan, que também é produtor musical do disco, começou a tocar algumas notas no baixo logo depois que ouviu a canção. Bruno começou a marcar o ritmo na bateria. E todos começaram a conversar e tocar sobre o que se transformaria na introdução instrumental da música.

Interessante esse trecho de diálogo porque encontramos um vocabulário próprio. Dustan pede para Boca menorizar um acorde. Boca interpreta rapidamente o que seu colega quis dizer. Menorizar, nesse caso, significa transformar um acorde maior em menor, modificando sutilmente a harmonia da introdução. Logo em seguida, Dustan pede para Bruno tocar só na cabeça. Ele quer dizer para o baterista entrar na cabeça do tempo, ou seja, marcar sua entrada no primeiro tempo do compasso. Para o guitarrista, ele diz "vamos tocar picadinho", ou seja, tocar as notas bem separadas uma da outra, sem ligação, picadas nesse sentido. Boca diz que vai tocar meio roquinho uma guitarra mais doidinha. $\mathrm{O}$ que pude perceber que ele fez nessa hora foi tocar suas frases com um efeito de pedal (distorção, no caso) e utilizando alguns bends (uma técnica utilizada para mudar uma nota tocada em instrumentos cordofônicos como guitarra ou baixo).

O diálogo todo é intercalado por sons, frases de guitarra e baixo e bateria, os músicos verbalizam suas ideias, mas precisam completá-las utilizando seus instrumentos. $O$ discurso verbal se mistura e se intercala com o discurso musical dos instrumentos. É como se as ideias de cada um não se completassem apenas com palavras. Ao final desse trecho, Boca diz "Toca aí tu e Bruno que aí eu..." e começa a tocar sua guitarra junto com os outros. Sua fala termina no ar e é completada, segundos depois, pelas frases de guitarra. Assim como os discursos se misturam, características humanas se misturam a coisas, aparentemente, não humanas. Frases, cabeça, doidinha, picadinho são termos utilizados pelos músicos nesses diálogos que remetem a domínios extramusicais.

Esse tipo de diálogo revela uma linguagem musical comum compartilhada por todos, característica que demarca um grupo sonoro. A linguagem musical está dividida em dois tipos de discursos "contrastantes mas com- 
plementares, que são componentes necessários do fazer musical e que também podem revelar como as pessoas pensam sobre música" (BLACKING, 2007, p. 207) - o verbal e o náo verbal. Analisar o modo como as pessoas pensam e fazem música passa pela análise desses dois tipos de discurso. Nos diálogos dentro de estúdio, no calor da criação, muitas vezes os músicos interrompem uma fala para tocar notas no instrumento, como no caso descrito acima. Apesar de separarmos esses dois discursos ao descrever esses processos, na prática eles caminham juntos.

Giovanni Cirino (2009), na sua etnografia da Música Popular Instrumental Brasileira (MPIB), observa que existe uma tradição oral-aural e uma tradição escrita na música. A MPIB incorpora aspectos das duas tradiçóes - ora mais popular, ora mais erudita - na visão de Cirino. No caso dessa gravação de disco, pode-se afirmar que predomina uma tradição oral-aural onde os discursos verbais e não verbais se complementam no processo criativo. Essa tradição oral-aural é a tradição musical na qual não existe partitura escrita, e o aprendizado acontece com base na capacidade de ouvir, memorizar e imitar.

\section{Intimidade com a tecnologia - o produtor musical como mediador entre técnica e arte}

O baterista do disco, Bruno Buarque, é também o proprietário do estúdio Minduca. Durante o primeiro dia de gravação, 5 de dezembro de 2011, ele fez de tudo um pouco: foi baterista, arranjador, engenheiro de gravação e técnico de som. No segundo dia, 6 de dezembro de 2011, Bruno decidiu chamar um assistente de gravação, cujo nome é Delăo Calvente, para apoiá-lo na operação dos equipamentos. Ele percebeu que seria muita coisa atuar como técnico de som, engenheiro de gravação, baterista e arranjador num único disco.

"Bruno (conversando com o assistente Delão): Curso rápido para você começar a fazer essa operação aqui. A gente vai gravar guitarra, baixo, bateria e voz juntos. Já tá tudo recado, ó! Ela tá na ordem do input, um, dois, três, quatro, cinco, seis, sete e oito. Aqui, ó! Tô trigando o bumbo e a caixa. Aqui os inputs. A guitarra tá no talo, ó! Se isso estourar é preocupante (aponta para algum marcador no equipamento). Se estourar a gente vai no pré correspondente e abaixa... Aqui você dá um maçã tab e ele vai pro apogi. Aqui você controla o volume do seu fone se ele estourar, dá um clear meters. Aqui reseta, sacou?! Para gravar aperta $\mathrm{R}$ de recordare, parar a 
gravação barra de espaço e maçã $S$ para salvar, quem ama salva!" (Diálogo no estúdio Minduca, 05/12/2011).

Esse curso rápido que Bruno Buarque ministrou em menos de três minutos, no segundo dia de gravação, revela a familiaridade que os músicos contemporâneos têm com a tecnologia. Esse diálogo seria difícil de ser imaginado numa gravação de disco nos anos 1980; um baterista atuando ao mesmo tempo como técnico de som, ensinando um jovem assistente a operar o equipamento no meio de uma gravação. No esquema das grandes gravadoras, onde cada um tem uma função bem definida, o dono do estúdio, o técnico de som, o baterista, o assistente e o produtor musical normalmente são pessoas diferentes. Morelli ([1991], 2009) apresenta uma boa descrição analítica do processo técnico e da divisão social da produção de discos dentro de grandes companhias fonográficas brasileiras, que se aprofunda na análise das relaçóes sociais de produção vigentes entre os diferentes tipos de trabalhadores artísticos e as gravadoras. Existe (ou existia) uma divisão do trabalho mais rígida dentro das grandes companhias fonográficas.

No fazer musical desses músicos e artistas contemporâneos, todo mundo acaba fazendo de tudo um pouco. Bruno Buarque não é simplesmente um baterista; é dono de um estúdio, é técnico de gravação, domina seu equipamento, dá ideias nos arranjos das cançôes, ajuda a equalizar e timbrar a guitarra e o baixo. Timbrar é o verbo utilizado para designar a atividade de trabalhar o timbre dos instrumentos e dos sons captados dentro do estúdio. É um termo muito utilizado pelos artistas, porém é bastante controverso. Dustan definiu timbre da seguinte forma:

\footnotetext{
"Timbre é uma palavra bonita que só... é um conceito, mas é sobre sensação... ou seja, subjetiva. São várias coisas ao mesmo tempo... a definição é simples, é tipo o resultado da variação da articulação aplicada numa nota musical qualquer (todas!)... É o RG (com foto!) de cada nota, o conceito é confundido (e generalizado, mas acaba sendo mais útil assim), com um efeito numa guitarra por exemplo... nem é isso. Você timbra cada nota... é massa... timbre é dessas palavras tipo 'estirpe'... quando usada metaforicamente... quase virando índole... Pronto! Timbre é a índole da nota musical...” (Entrevista com Dustan Gallas, 18/12/2011).
}

Em entrevista com o guitarrista Boca, perguntei o que significa "timbrar um instrumento". Ele me explicou o seguinte: 
"Cara, acho que você não timbra o instrumento, você timbra o som, né? $\mathrm{O}$ instrumento já vem com timbre definido. Uma guitarra ou violáo de determinada marca tem seu timbre característico... você liga ele no amplificador e vai timbrar o som mexendo no equalizador ou no que mais for... mas o timbre do instrumento já é dele próprio, a guitarra e o baixo.” (Entrevista com Junior Boca, 23/03/2012).

Dustan, Bruno e Boca se preocupam bastante com o timbre dos instrumentos. Fazer música passa pela responsabilidade com a "índole" e a "cor" das notas. É como se a nota tivesse um aspecto moral (índole) e um visual (cor). Essa elaboração verbal de timbre caminha lado a lado com noçóes técnicas de áudio (altura, intensidade, duração). Os músicos têm que tocar bem seus instrumentos, fazer as notas soarem bem, saber gravar, equalizar, criar arranjos etc. Se por um lado ficam sobrecarregados de funçóes, por outro ganham uma autonomia criativa sem precedentes no mundo fonográfico.

A fala de Bruno para Deláo fica difícil de acompanhar quando ele começa a utilizar os jargóes técnicos de sua prática musical multifacetada dentro do estúdio. Quando diz "Já tá tudo recado", por exemplo, está afirmando que os canais dos instrumentos estão ativados no software de gravação. Input é a entrada, é por onde o sinal de áudio dos instrumentos chega no equipamento de gravação. Trigando é um termo que vem de trigger, gatilho em inglês, para quando o sinal de áudio de uma parte da bateria está sendo duplicado por um sample. Sample também vem do inglês e pode ser traduzido como amostragem. Normalmente, uma amostragem de outra música que foi recortada e reutilizada. Nesse diálogo, Bruno afirma que bumbo e caixa, duas partes da bateria, estão trigadas, ou seja, quando tocadas acionam um gatilho que dispara um sample (provavelmente um som diferente de bumbo e caixa que Bruno recortou de outra música para somar com som natural de seu instrumento).

Talo significa que o volume está no limite mais alto possível. Maçã Tab são as teclas do computador Apple que executam determinado comando no software. Enfim, existe um língua paralela neste mundo tecnológico dos estúdios de gravação. Os músicos e artistas que gravam discos acabam aprendendo na prática os termos e jargóes técnicos desse fazer musical. $\mathrm{O}$ qual é caracterizado pelo domínio do instrumento musical propriamente dito (uma bateria no caso do Bruno Buarque) e pelo domínio dos processos técnicos de gravação (que envolvem os conhecimentos necessários para a operação de softwares, dos equalizadores, pré-amplificadores, compressores e microfones). Tal domínio de múltiplas tarefas e conhecimentos 
caracteriza esse grupo sonoro do qual fazem parte diversos músicos de São Paulo. Devido à proliferação desse tipo de domínio técnico entre eles, a gravação de discos se proliferou e ganhou força ao longo da primeira década do século XXI. Essa junção dos aspectos técnicos com os aspectos artísticos caracteriza o trabalho de produção musical.

Uma definição mais formal do que é um produtor musical me foi fornecida por Guilherme Kastrup, baterista e produtor musical que já realizou trabalhos com Kiko Dinucci e Rodrigo Campos. Segundo Kastrup, o produtor musical "é aquele responsável por aliar a parte técnica com a parte artística, fica no meio do caminho entre o artista e os equipamentos do estúdio, tem que tentar traduzir o que o artista quer dizer através dos meios técnicos disponíveis". O produtor musical aparece aqui como um mediador de dois universos - o técnico e o artístico. Ora, acabamos de ver que uma característica que marca esse grupo é que todos possuem um bom conhecimento técnico aliado ao artístico. Isso significa que todos envolvidos são em alguma medida produtores musicais - o baterista Bruno, o guitarrista Boca, o baixista e tecladista Dustan e o cancionista Tatá.

Todo artista desse grupo sonoro é em alguma medida um mediador de universos diversos. Para realizar seu disco, o artista compóe, capta recursos financeiros e materiais, monta uma equipe (uma banda, um produtor musical), define qual o melhor estúdio, quais equipamentos de que precisa, define a arte da capa e elabora uma estratégia de lançamento e de vendas. Ele faz a mediação entre todas essas etapas que seriam o lado mais técnico de seu fazer musical. Kiko Dinucci é um dos artistas que lançou mais discos nos últimos anos. Apesar de não ter um home studio, ele afirmou em entrevista que tem seu esquema para lançar os discos.

"Gravar um disco é sempre um negócio difícil, não vou falar que é um negócio fácil. $\mathrm{Na}$ hora que você manda um disco pra fábrica e já arrumou a capa, aí a capa dá problema no arquivo, e autorização, e não sei quê, não sei quê... aí você fala: 'Meu, que vendaval, vou ficar cinco anos sem gravar disco agora pra não passar por tudo isso de novo'. Mas, por exemplo, com o Metá-Metá também deu muito trabalho. A gente lançou no virtual, mas a gente lançou naquele esquema dentro do Bagagem de ter um vídeo pra cada música, daí a gente tinha que ficar cobrando vídeo dos artistas, os artistas fazendo vídeo em cima da hora, com data pra lançar e coisa e tal. Foi uma coisa que deu muito trabalho, o virtual também dá muito trabalho. $\mathrm{O}$ disco sempre dá muito trabalho. Por outro lado, pra mim tá muito mais fácil gravar. Se eu tiver 
mil e quinhentos reais no bolso eu gravo um disco; o meu preço de estúdio é esse. Entro lá ensaiado, um-dois-três-quatro, dois takes pra cada música, depois vou gastar mais um pouco com a mixagem e a masterização e a capa vai estar pronta, a capa pode ser algum amigo que faça e eu dou a grana depois.” (Entrevista com Kiko Dinucci, 23/04/2012).

Mesmo sem dominar a parte técnica da captação do áudio como Bruno Buarque, artistas como Kiko Dinucci conseguem viabilizar sua arte e produzir seus discos. Eles se associam aos parceiros certos e tornam a produção fonográfica de seus trabalhos algo relativamente fácil e barato. Criam seus esquemas de produção. Esquemas calcados em relaçóes interpessoais de amizade e confiança com pessoas como Bruno Buarque (capazes de mediar com competência a arte e a técnica), calcados em recursos financeiros e materiais próprios (Kiko gravou os discos do Metá-Metá com cachês de shows, Tatá gravou os discos do seu grupo Cérebro Eletrônico e seu disco solo com recursos próprios e ajuda de sites de crowdfounding ${ }^{4}$ como o $\mathrm{Ca}$ tarse), possibilitando uma autonomia criativa quase absoluta. Tatá utiliza a expressão "alforria artística" para falar dessa situação. A noção de "grupo sonoro” (BLACKING, 2007) é boa pra pensar essa realidade - essas pessoas compóem, a meu ver, um novo grupo sonoro formado por músicos que compartilham alguns elementos importantes: 1) referências musicais; 2) tecnologias de produção musical; 3) tecnologias de divulgação e distribuição da música gravada via redes sociais na internet; 4) a noção de que é fundamental gravar discos autorais; 5) valorizaçáo da autonomia criativa.

Observamos diversas falas dos músicos, mas o que os discos e os equipamentos de estúdio nos dizem enquanto agentes? Os computadores nos quais são gravados os sons tocados pelos instrumentos dizem-nos que o acesso à gravação está facilitado e que muitos artistas e bandas podem produzir seus discos. Esse acesso à tecnologia de produção tornou mais fácil gravar discos. $\mathrm{O}$ disco se torna um agente compartilhado por estes artistas. Os discos dizem quem são esses artistas, tornam o nome deles algo público, fazem sua pessoa circular e se desprender de seu próprio corpo. Esses agentes não humanos estão dizendo que é fundamental gravar porque os discos fazem os artistas tanto quanto os artistas fazem os discos.

Podemos pensar diversas situaçóes e formas de agência do disco sobre o artista. O disco faz o artista ao promover encontros deste com outros músicos, ao enriquecer os arranjos de uma canção, ao fazer o nome do artista circular de forma mais ampla (seja na internet, nas mídias tradicionais ou entre os próprios músicos e ouvintes apreciadores) e ao dar forma a uma 
obra musical autoral e apresentá-la ao grande público. O disco é um objeto, mas é também um sujeito que age na vida dos artistas que os produzem. Dizer que o disco é um agente implica em reconhecer que todos os equipamentos de áudio que um músico consegue adquirir estão agenciando transformações em sua vida. O baterista Bruno Buarque, sem seu software de gravação, sem seus microfones, sem seus pré-amplificadores seria um outro Bruno Buarque e faria música de outro jeito. Mas por que ele adquiriu esses equipamentos? Parar realizar gravaçóes de discos.

Possuímos centenas de mitos contando como o sujeito (ou o coletivo, ou a intersubjetividade, ou as epistemes) construiu o objeto - a revoluçáo copernicana de Kant sendo apenas um exemplo de uma longa linhagem. Náo temos, entretanto, nada para nos contar outro aspecto da história: como o objeto faz o sujeito. (LATOUR, 2009, p. 81)

Latour fala em "quase-objetos" e "quase-sujeitos" lançando reflexōes provocadoras às posiçôes absolutas das entidades no mundo moderno. $\mathrm{O}$ esforço intelectual de sua antropologia é fugir das posiçóes absolutas. Lançando este tipo de olhar aos discos e aos processos criativos envolvidos na sua constituição fica claro sua importância dentre os membros do grupo sonoro analisado aqui. Fica claro que os artistas agenciam os discos, mas também são agenciados por eles.

\section{Dinâmicas coletivas de arranjo - quem é o artista?}

Marcelo Cabral é um baixista e produtor musical respeitado na cena musical atual. Ele produziu o disco Nó na orelha do rapper Criolo, considerado pela crítica especializada uma das grandes revelaçóes da música. Cabral faz parte dessa etnografia porque trabalha com Rodrigo Campos e com Kiko Dinucci em várias situaçóes. Ele gravou o disco Bahia fantástica, faz parte do Metá-Metá (grupo liderado por Kiko Dinucci, Juçara Marçal e Thiago França) e é membro do Passo Torto (grupo formado por Cabral, Kiko, Rodrigo e por Rômulo Fróes). Durante um ensaio preparatório para a gravaçáo do segundo disco do Passo Torto, ouvi Cabral dizer uma das frases mais interessantes sobre produçáo musical.

"Quanto menos pronta a canção chega, mais legal é de produzir. Quanto mais pronta, com melodia, harmonia, refrão, mais difícil é!" (Ensaio do Passo Torto, 24/02/2013) 
Essa fala revela um característica importante dos processos de produção musical que pude observar durante a pesquisa - o caráter coletivo dessa produção. Essa geração de músicos estabeleceu uma dinâmica coletiva de produção musical bastante peculiar. Quanto menos pronta a canção de alguém chega, mais os outros podem criar e acrescentar. Os arranjos dos discos são criados coletivamente, todos dão ideias, todos se comportam como se não fossem apenas responsáveis pelo seu instrumento, a figura do instrumentista é suplantada pela figura do artista. Cada envolvido é também artista, mesmo quando o disco leva o nome de um só, ele é de vários. Rodrigo Campos, em seu Bahia Fantástica, deixa claro no encarte do disco que a produção musical e os arranjos são de todos. Em uma entrevista na sua casa, no bairro de Pinheiros, em São Paulo, ele comentou:

\footnotetext{
"Então, agora eu estou fazendo de um jeito diferente, um jeito mais coletivo. Eu estou dirigindo a parada, mas de uma maneira sutil. Chamei o Rômulo Fróes para dirigir junto comigo e montei uma banda. A banda são os produtores - entáo cada um dos músicos vai dar a contribuição, a gente vai gravar ao vivo... É um jeito que eu ainda não vi ser feito dos músicos assinarem a produção mesmo." (Entrevista com Rodrigo Campos, 25/05/2011).
}

Tatá Aeroplano também reconhece que seu disco é de todos. Ele promete revolucionar a questão dos direitos autorais de suas cançôes repassando um percentual de autor para todos os músicos. Ele se mostra bastante satisfeito e feliz com o resultado sonoro do disco. Em sua opiniáo, Dustan Gallas, Junior Boca e Bruno Buarque souberam respeitar suas cançóes, eles "ouviram as cançóes, entenderam as histórias que elas contavam”. Boa parte do que pude observar nos dias que passei com esses músicos se resumiu à audição das cançóes e à adição de camadas a partir da compreensão coletiva da estrutura delas. Antes de gravar cada canção, eles ouviam juntos as guias que Tatá havia gravado somente com voz e violão para, então, iniciarem o trabalho de produçáo. Ficou claro, durante esses momentos, que o músico antes de começar a gravar tem que se comportar como audiência. Quanto menos músico e quanto mais audiência ele for, mais se aproximará do artista; seu trabalho de produção da canção, propriamente dito, terá mais resultado. Os discos gravam os artistas e transformam músicos em audiências. Essa audiência também se comporta como um artista quando passa a construir coletivamente a canção.

A dinâmica desse trabalho, apesar de dirigida por Dustan Gallas e pelo próprio Tatá, foi bastante coletiva na medida em que todos davam ideias 
e sugestóes de arranjo musical. Esses arranjos não eram escritos em partituras, as ideias eram experimentadas e gravadas em novas versóes guia conforme iam surgindo. Não existe separação clara entre arranjador, intérprete, compositor, instrumentista. As fronteiras entre essas categorias são borradas; talvez a que permaneça mais intacta e "pura" seja a figura do compositor, mas Tatá Aeroplano insiste que seu disco é de todos, ele cita os músicos como coautores das cançôes. Essa noçáo de arranjo que emerge na observação do fazer musical desse grupo é bastante particular se comparada a uma visão mais acadêmica e tradicional. "O estudo do arranjo muito tem a ver com o da composição: ambos dependem de matérias teóricas fundamentais: a harmonia, o contraponto, a morfologia e a instrumentação" (ALMADA, 2010, p. 17).

Esse trecho, retirado da introdução de um livro formal de arranjo do professor da UFRJ Carlos Almada, indica uma necessidade de conhecimentos teóricos que nem sempre estáo presentes entre os membros desse grupo. Quando alguém vai estudar arranjo na universidade, está implícito que estará lidando com grandes massas instrumentais que exigem amplo conhecimento teórico, e "o arranjador deve desenvolver, por meio da experiência pessoal e de muitas análises" (ALMADA, 2010, p. 343) uma noção de forma, de equilíbrio e de como empregar bem cada instrumento. $\mathrm{O}$ arranjador tradicional é um especialista em instrumentaçôes volumosas. Os arranjos devem ser escritos numa partitura e normalmente são uma criação individual. Quando os músicos analisados aqui falam em arranjo, estáo tratando de um outro tipo de arranjo. Um arranjo que é coletivo, não exige domínio teórico profundo, náo opera com instrumentaçóes volumosas, náo opera com partitura escrita.

Essa dinâmica de arranjos coletivos predominou no processo de criação dos três discos que acompanhei, Tatá Aeroplano, Bahia fantástica, do disco Metal-Metal, entre outros. É um modo de produçáo que esse grupo sonoro encontrou para trabalhar as cançóes inéditas de cada compositor. Um modo de produção que funciona sem arranjos pré-concebidos individualmente por um arranjador de fora, funciona com base na amizade e confiança que cada músico estabelece com o outro. Um modo de produção que se estabeleceu em parte por uma questáo de necessidade, como afirma o compositor Rômulo Fróes, que participou do segundo disco de Rodrigo Campos, Bahia fantástica, num vídeo divulgado no YouTube:

"O convívio com os outros artistas foi necessário. Você até pode fazer seu disco inteiro lá na sua casa, mas, enfim, qual a graça que tem isso, né? Compartilhar a sua música e mostrar a sua música pro outro artista e querer que esse outro artista 
contribua pro seu trabalho, além da coisa óbvia de admiração por esse outro artista, tem a coisa da necessidade mesmo! Olha, eu toco violáo no seu disco, você toca bateria no meu, eu faço uma letra pra você, pra sua canção, e você canta no meu disco. É isso, vamos aí, vamos fazer essa coisa juntos, porque eu tô precisando de um baterista e eu não tenho dinheiro pra pagar um baterista, mas eu toco violáo pra você! Então, tem uma necessidade de sobrevivência em cima de tudo isso que acabou gerando mais tarde amizades e identidades artísticas." (trecho da fala de Rômulo Fróes). ${ }^{5}$

Na própria fala reproduzida acima, percebe-se como as categorias se borram no discurso nativo. Rômulo começa afirmando a necessidade de os artistas se ajudarem e termina falando do baterista de que ele precisa para gravar. Os instrumentistas são artistas e vice-versa. Entretanto, vale dizer que esse modo de produção musical que estou chamando de coletivo não é grande novidade nas gravaçóes de disco. Náo quer dizer que esse grupo de artistas está inventando um jeito coletivo de fazer música. Se pensarmos no surgimento do Jazz, grandes discos foram gravados de forma improvisada e coletiva, sem arranjos pré-concebidos. Ou mesmo na história do Rock veremos que várias bandas surgiram de grupos de amigos que compunham e criavam coletivamente. Essa dinâmica coletiva de criação é uma característica desse grupo, apesar de não ser uma invenção dele ou uma marca única que o distingue de outros grupos sonoros. $\mathrm{O}$ que pode distinguir esse grupo é essa dinâmica coletiva aliada a um domínio tecnológico dos meios de produção musical inédito - um curto circuito entre a parte artística e a parte técnica. ${ }^{6}$ Não existem mais intermediários entre uma ponta e outra, esses jovens artistas dominam todas as etapas e se localizam numa região ambígua.

\section{El Rocha - Metá-Metá}

Em junho de 2012, a banda Metá-Metá se reuniu no estúdio El Rocha (Pinheiros, São Paulo) para gravar seu segundo disco, Metal-Metal. O projeto iniciado pelo trio Kiko Dinucci, Juçara Marçal e Thiago França se tornou uma banda maior com a entrada oficial de Marcelo Cabral, Sérgio Machado e Samba Sam. Os arranjos foram feitos nessa dinâmica coletiva, com predominância de discursos não verbais sobre os discursos verbais. Porém, diversamente do que observei no disco de Tatá Aeroplano, no qual os arranjos foram feitos durante a gravação, no Metal-Metal os arranjos musicais estavam prontos quando se iniciaram as gravaçóes. O grupo ensaiou e tocou junto em shows, antes de entrarem no El Rocha para o primeiro dia de gravação. 
Num dos dias em que acompanhei a banda, cheguei ao El Rocha por volta das onze horas da manhá. Durante a primeira hora de gravaçáo que presenciei, eles ouviram uma música que haviam gravado no dia anterior. Montaram os microfones para Rodrigo Campos e Thiago França gravarem overdubs (gravaçóes sobrepostas ao que já foi gravado) de cavaquinho e saxofone sobre os outros instrumentos gravados ao vivo. Por coincidência, nesse dia em que acompanhei o Metá-Metá, Rodrigo Campos fazia uma participação especial, tocando cavaquinho em algumas músicas do disco.

Depois de uma pausa para o almoço, de aproximadamente uma hora, voltamos todos para o estúdio para continuar gravando. Eles começaram a gravar a música "Logun". Fiquei observando na técnica, sala onde fica o técnico de som e onde Juçara Marçal gravaria sua voz isolada do resto da banda. Como o próprio título prenuncia, "Logun", nome de um orixá masculino "filho de Oxóssi com Oxum... príncipe do encanto e da magia" (PRANDI, 2001, p. 137), é uma música bastante influenciada pela sonoridade afro-brasileira. Poderia ser considerada como do gênero Afrobeat, caracterizado pela repetiçáo de um groove central e pelos ricos arranjos com instrumentos de sopro e mundialmente conhecido devido à obra do artista nigeriano Fela Kuti.

"Logun" começa com um violáo bastante complexo, de Kiko Dinucci, fornecendo o cerne do groove, o centro rítmico e tonal da composição. Baixo e bateria entram na sequência, dialogando com a levada do violão. $\mathrm{O}$ cavaquinho entra fraseando, sendo sucedido por um tema forte de sax. Juçara aguarda, dançando, seu momento de entrar. Após a entrada dos sopros, tudo some novamente, restando violão, baixo e bateria. A gravação acontece, dura cerca de oito minutos. Os instrumentos conversam sem parar, os músicos estão todos concentradíssimos para fazer valer esse take $e^{7} \mathrm{da}$ música. Ao término, todos deixam seus postos e entram na técnica, onde estávamos eu, Juçara e Fernando Sanches, o técnico de gravação e filho do proprietário do El Rocha.

Ao fim da audição coletiva da gravação que acabaram de fazer, todos comentam que um erro ocorrido no final acabou ficando "legal". A performance ao vivo de todos está táo boa que eles resolvem que o erro vai se tornar acerto; eles o incorporam sem problemas. $\mathrm{O}$ erro em questão é uma sobra de bateria e percussão, ou seja, depois que todos pararam de tocar, o baterista e o percussionista continuaram tocando algumas notas. Não é raro isso acontecer numa gravação - o erro e o ruído serem incorporados -, especialmente em performances ao vivo, com vários instrumentos sendo tocados ao mesmo tempo. Isso também é comum em músicas com espaço para improvisação, como é o caso de "Logun". No caso da MPIB, Cirino afirma que o "erro" é sempre lembrado pelos entrevistados como algo re- 
lativo, porque abre perspectivas de novas ideias e a partir dele "pode surgir uma outra atitude". Essa nova atitude que incorpora o erro acaba, por um lado, incentivando o instrumentista a se arriscar mais e, por outro, cria o impacto, o susto e o suspense" (CIRINO, 2009: 65). Há um momento em que Kiko Dinucci e Rodrigo Campos improvisam variaçóes rítmicas em seus instrumentos que dificilmente poderiam ser reproduzidas da mesma forma novamente. Se eles optassem por náo utilizar esse take, perderiam esse diálogo.

"Kiko Dinucci: Sempre dá certo, eu faço qualquer coisa que dá certo (falando sobre as levadas rítmicas que tocou).

Rodrigo Campos: Parece briga de galo! (risos.)

Fernando Sanches: Fazer overdub ia ficar estranho!

Kiko Dinucci: Tem que ser os dois juntos."

O El Rocha é um estúdio bastante requisitado na cena musical de São Paulo. É bem maior e mais antigo que o Minduca, de Bruno Buarque, e conta com uma infraestrutura mais complexa. Ele permite que todos toquem juntos, mas para isso tem que isolar o som de cada instrumento, o que no caso dos instrumentos acústicos representa uma necessidade de isolamento físico. Eles tocam juntos, porém separados. O estúdio carrega essa contradição; separar o que está junto e isolar acusticamente o que deve soar coletivamente ao final do processo. Para que Kiko e Rodrigo possam conversar com seus instrumentos, eles estão conectados pelo que escutam em fones de ouvido; fisicamente, estáo separados em pequenas salas. Se Kiko e Rodrigo se escutam "sempre dá certo"; tudo que um toca, o outro responde e vice-versa.

Essa característica de isolamento acústico que um estúdio possui é fundamental para a manipulação sonora que uma gravação de disco exige. $\mathrm{O}$ som, para ser manipulado, deve ser capturado de forma isolada, dito de outra forma, de forma pura. Cada instrumento é "purificado" para depois ter seu som manipulado com todos os recursos tecnológicos disponíveis. Esse tipo de operação calcado na purificação e isolamento de agentes lembra muito o que ocorre dentro de laboratórios científicos. O antropólogo Stélio Marras (2009) traz uma boa descrição dos laboratórios como recintos e compara a atividade dos agentes humanos em relação aos agentes não humanos com um maestro e uma orquestra.

Nos laboratórios, os recintos parecem simular o mundo sob controle. Como ambientes de alta domesticaçáo científica, eles fazem passar do indeterminado para o determinado, do 
indiferenciado ao diferenciado. Podem reter o tempo ou acelerá-lo. No espaço dos envoltórios, containers, caixas, tubos, garrafas e mesmo salas ou equipamentos de acesso restrito, os recintos formam um ambiente que, como tal, cerca fronteiras entre o interior e o exterior, age diretamente no controle de variáveis, controle de permanências, engendram proibições e permissôes, entradas e saídas de uma multiplicidade de agentes. A própria agência humana parece a de um maestro de uma orquestra rebelde, teimosa, vulnerável, custosa para domesticar. (MARRAS, 2009, p. 31)

Marras se inspira em Latour, e para ambos o laboratório é um recinto onde não humanos se fazem aparecer enquanto sujeitos. Nos laboratórios, o microscópio revelou ao mundo a existência das bactérias. A bomba de ar revelou ao mundo a existência do vácuo. Pensar os estúdios na mesma chave nos leva a reconhecer que seus equipamentos de domesticação sonora revelam ao mundo o timbre, as alturas, as frequências, as durações de cada nota tocada. Revelam também como uma música é construída a partir de dinâmicas coletivas de criação em que os discursos verbais e náo verbais se complementam o tempo todo. Revelam como discos e artistas se afetam mutuamente.

\section{Considerações finais: curto-circuito entre arte e técnica}

A partir de uma perspectiva etnográfica, busquei descrever fazeres musicais contemporâneos para os quais a produção de discos autorais é central, ou seja, realizei uma etnografia musical dos discos em construção. A etnografia musical é sempre uma etnografia do processo de fazer música, das relaçóes sociais estabelecidas por causa da música; nesse caso, um fazer musical que é um fazer discográfico. É nessa chave que leio autores como Seeger e Feld, citados logo no início deste artigo. Os discos em construção podem ser entendidos também como os próprios artistas em construçáo. O disco se apresenta como um objeto artístico que encerra uma série de associações, é um artefato constituído por, e que também constitui, diversas relações sociais. Social aqui entendido como associação, tanto a associação de músicos entre si quanto a associação de músicos com instrumentos e computadores.

Descrever as relaçóes sociais por trás da música, produzida por um grupo de compositores em Sáo Paulo, passa necessariamente pelas relaçóes sociais envolvidas na produçáo de seus discos. O disco, aparentemente ob- 
soleto por ter perdido valor enquanto mercadoria, ou por ter se desmercantilizado se levarmos em conta sua vida social (Appadurai, 2008), emerge como um sujeito sonoro que revela as associaçóes humanas e não humanas constituintes de fazeres musicais contemporâneos. Sua observação revelou características importantes sobre as maneiras pelas quais um grupo sonoro urbano faz música e sobre como essa música faz o grupo. Dentre as principais características observadas, destaco as seguintes:

- Dinâmicas coletivas de arranjo: Cada canção, que um ou mais compositores trazem para uma gravação, passa a receber camadas melódicas, rítmicas e harmônicas de todos os músicos envolvidos no processo. Todos possuem liberdade para sugerir e opinar na hora de produzir a canção.

- Multiplicidade de competências (musicais, técnicas e artísticas): Músicos, intérpretes, arranjadores, compositores, técnicos de som, produtores musicais são categorias que se misturam em cada pessoa envolvida com o disco. Essas fronteiras, antes mais claras e precisas, estão sendo borradas. Existe um sentimento comum de que a gravação é de todos, mesmo quando se trata de um disco solo. Existem os profissionais especialistas, mas predominam os profissionais que englobam diversas competências no seu fazer musical.

- Músicos se colocando como audiência e como artistas: Isso está ligado à noção de que a visão do instrumentista virtuoso é muito limitada a visão dos leigos e dos artistas é mais ampla no que diz respeito a cançôes. É a ideia de que um baterista não vai executar automaticamente o ritmo do samba ou do baião; ele deve antes escutar a canção, se apropriar artisticamente dela para poder saber o que e como tocar. Nesse grupo sonoro, o virtuosismo técnico do instrumentista não é valorizado; é valorizado o instrumentista que se comporta como o artista, pensando a canção de forma mais ampla.

- O que é produçáo musical: Produção musical aqui é entendida como essa capacidade de unir arte e técnica. Capacidade compartilhada por muitas pessoas nesse grupo. Todo artista se comporta, em alguma medida, como produtor musical em relaçáo à sua obra. No caso de cançóes, a produção está ligada à melhor tradução possível do que o compositor quer dizer com os meios técnicos adequados. Isso passa pela escolha do melhor estúdio, dos músicos e dos instrumentos, da pessoa que fará a mixagem e a masterização. 


\section{- A gravaçáo do disco como o momento de "gravaçáo de artistas":} Como disse anteriormente, e vale repetir, o disco produz o artista ao promover encontros deste com outros músicos, ao enriquecer os arranjos de uma canção, ao fazer o nome do artista circular de forma mais ampla (seja na internet, nas mídias tradicionais ou entre os próprios músicos e ouvintes apreciadores) e ao dar forma a uma obra musical autoral e apresentá-la ao grande público. Sendo a performance musical algo táo efêmero, o disco é o agente capaz de perenizar uma obra musical.

Todas essas características reunidas compóem um quadro interpretado aqui como um curto-circuito entre arte e técnica. A grande novidade presente nesse grupo sonoro, e talvez em toda uma geração de músicos, é que, neste início do século XXI, os artistas dominam as tecnologias criativas do setor fonográfico. Isso transforma profundamente o modo como se pensa e se faz música. Transforma também o disco enquanto objeto-sujeito artístico. Autores como Tosta Dias $(2009,2011)$ e Herschmann $(2010,2011)$ falam da perda da centralidade do disco, do aumento da importância dos shows ao vivo. Concordo em parte com eles, o disco perdeu centralidade enquanto mercadoria, mas ganhou uma centralidade sem precedentes enquanto agente no fazer musical contemporâneo.

O discurso nativo dos artistas e músicos indica que, entre outras coisas, quando eles pensam em música autoral, ainda pensam em discos. A hipótese que se configura aqui é que isso ocorre por conta desse curto-circuito entre arte e técnica. A regiáo em curto revela uma proliferação de agentes os próprios discos, os estúdios, os computadores, os softwares de gravação, mas também os artistas que não são mais apenas artistas, são produtores musicais, arranjadores e instrumentistas. Humanos e não humanos envolvidos nesse fazer musical conectam arte a técnica, polos que no auge da grande indústria fonográfica estavam separados de forma mais clara.

Os discos persistem porque agem socialmente. Eles produzem artistas. Transformam as experiências pessoais destes em experiências que podem ser compartilhadas. Ao lançar um disco, o artista está dizendo para o resto do mundo que ele tem algo diferenciado, ele está criando uma identidade artística, consolidando sua estética, se distinguindo de outros músicos. "Existir é diferir: na verdade, a diferença é, em certo sentido, o lado substancial das coisas, o que elas têm ao mesmo tempo de mais próprio e de mais comum" (TARDE, 1998, p. 98). Ao diferir através do disco, o artista existe enquanto tal, porém também se assemelha a outros que, como ele, estão gravando seus trabalhos. 
A música pode ser especialmente útil no estabelecimento da identidade de um grupo, junto aos estilos de vestuário e discurso. Mesmo quando estilos de vida mudam, a forma da aldeia é abandonada, os pássaros cujas penas são utilizadas em ornamentos sáo extintos, roupas são usadas, e a língua nativa é esquecida, membros de um grupo podem empregar canto e dança para indicar o que eles gostariam de ser numa dada ocasiáo e para restabelecer uma continuidade com seu passado. Talvez seja por isso que grupos táo fragmentados se apegam a suas tradiçôes musicais com uma tenacidade que não manifestam para mais nada. (SEEGER, 2004, p. 137)

Mesmo tratando de uma realidade social completamente diversa, essa questão da importância da música para a manutenção de uma identidade grupal pode ser útil para se pensar fazeres musicais urbanos. Kiko Dinucci, Rodrigo Campos, Tatá Aeroplano e todos os músicos e artistas citados neste texto podem ser pensados como membros de um grande grupo sonoro. Um grupo sonoro formado por centenas de outras pessoas e que se diferenciam de outros músicos pelo fato de produzirem um conteúdo sonoro autoral.

Os discos de Tatá, Rodrigo e Kiko são únicos, mas existem traços repetidos nos três. Dentre os traços comuns, o curto-circuito que o domínio tecnológico pelos artistas gerou é o mais distintivo. Um curto-circuito elétrico acontece quando uma carga elétrica maior passa entre dois pontos com impedâncias diferentes. Isso ocorre quando a resistência elétrica dentro do circuito diminui por algum motivo. No caso da produçáo fonográfica, a resistência era o alto custo de um disco e o monopólio dos meios de divulgação e circulação. As tecnologias digitais e a internet derrubaram essas duas barreiras, causando esse curto-circuito no antigo esquema do universo fonográfico. Uma avalanche de artistas solos e bandas que sempre desejaram gravar suas obras se viu numa posição inédita com os meios e ferramentas técnicos à disposição. Isso está gerando uma revolução nos fazeres musicais e uma profunda reconfiguração do disco enquanto obra de arte.

\section{Notas}

1. Para citar duas grandes etnografias musicais, lembremos que Anthony Seeger, em Why Suyá Sing (2004), analisa a Mouse Ceremony, as relações entre irmãos, a organização etária, a mitologia, entre outros elementos, para abordar a música desse grupo. Steven Feld, em Sound and Sentiment 
(1982), trata da etnobotânica e da complexa classificação dos pássaros na sociedade Kaluli para analisar seus cantos. Feld recorre a um mito em que o irmão mais novo é abandonado pela irmã mais velha, a qual se transforma em pássaro, para dar conta da complexidade musical de um determinado tipo de canto.

2. Vale inserir aqui um breve comentário sobre a relevância artística dos nomes escolhidos, a qual se expressa pelo volume da obra musical produzida (cada um deles já lançou mais de três discos próprios), pelo volume de shows e concertos que realizam, na cidade de São Paulo, em locais consagrados como os palcos dos SESCs (Serviço Social do Comércio), e pela visibilidade que alcançam em mídias impressas e de internet. Eles são interlocutores relevantes por serem extremamente ativos nessa cena musical paulistana.

3. Alguns discos relevantes produzidos nesses estúdios durante o período da pesquisa - além dos álbuns de Tatá Aeroplano, Kiko Dinucci e Rodrigo Campos que serão analisados aqui - foram: Nó na orelha, de Criolo, gravado no El Rocha; Efêmera, de Tulipa Ruiz, gravado no YB; e Longe de onde, de Karina Buhr, gravado no Minduca. Para se ter uma ideia imediata da relevância desses trabalhos, basta conferir as listas de melhores discos nacionais de 2011 e 2012 publicadas pela revista especializada em música Rolling Stone. Todos esses discos figuram nas listas dessa revista e de outras importantes mídias brasileiras.

4. Financiamento coletivo de projetos diversos, normalmente através de sites na internet.

5. Disponível em: https://www.youtube.com/watch?v=65MWP_qDcx0. Última visualização dia 16/04/2016.

6. Devo essa ideia de "curto-circuito" entre arte e técnica ao antropólogo Pedro Lolli, que em vários momentos me auxiliou com suas leituras das primeiras versóes deste texto.

7. Take nesse contexto significa uma tomada da música gravada. Quando se está gravando uma canção, é comum repetir várias tomadas, cada tomada ou repetição é um take.

8. Vale notar aqui como o vocabulário musical fornece agência aos instrumentos e às notas tocadas. Nesse trecho, Rodrigo Campos brinca que as melodias do cavaquinho e do violão parecem galos brigando. Em outros momentos, os músicos falam das "frases" da guitarra, dos instrumentos "dialogando", "conversando". O vocabulário utilizado por músicos populares humaniza os instrumentos musicais. 


\section{Referências bibliográficas}

ALMADA, Carlos. Arranjo. Campinas: Editora da Unicamp, 2010.

APPADURAI, Arjun. Introdução: mercadorias e a política de valor. In: $A$ vida social das coisas: as mercadorias sob uma perspectiva cultural. Niterói: Editora da Universidade Federal Fluminense, 2008.

BLACKING, John. Música, cultura e experiência. Cadernos de campo, vol. 16, n. 16, São Paulo, 2007.

CIRINO, Giovanni. Narrativas musicais: performance e experiência na música popular instrumental brasileira. São Paulo: Annablume, Fapesp, 2009.

DIAS, Marcia Tosta. Os donos da voz: indústria fonográfica brasileira e mundialização da cultura. Sáo Paulo: Boitempo, 2008.

FELD, Steven. Sound and Sentiment: birds, weeping, poetics, and song in Kaluli expression. Pennsylvania: University of Pennsylvania Press, 1982.

HERSCHMANN, Micael. Nas bordas e fora do mainstream musical: novas tendências da música independente no início do século XXI. São Paulo: Estação das Letras e Cores, 2011.

. Indústria da música em transição. São Paulo: Estação das Letras e Cores, 2010.

LATOUR, Bruno. Give Me a Laboratory and I will Raise the World. In: KNORR-CETINA, K.; MULKAY, M. (Eds.). Science Observed: perspectives on the social study of science. Londres: Sage, 1983, p. 141-170.

. Ciência em ação: como seguir cientistas e engenheiros sociedade afora. São Paulo: Editora Unesp, 2000.

. A esperança de Pandora: ensaios sobre a realidade dos estudos científicos. Bauru: Edusc, 2001.

. Jamais fomos modernos. São Paulo: Editora 34, 2009.

MARRAS, Stélio. Recintos e evolução: capítulos de antropologia da ciência e da modernidade. Sáo Paulo, 2009. Tese (Doutorado em Antropologia) - Departamento de Antropologia FFLCH/USP.

MERRIAM, Alan P. The Anthropology of Music. New York: Northwestern University Press, 1964.

MORELLI, Rita C. L. Indústria fonográfica: um estudo antropológico. Campinas: Editora Unicamp, 2009.

PRANDI, Reginaldo. Mitologia dos orixás. São Paulo: Companhia das Letras, 2001.

SEEGER, Anthony. Etnografia da música. Cadernos de campo, vol. 17, n. 17, São Paulo, 2008.

Why Suyá Sing: a musical anthropology of an Amazonian people. Cambridge: Cambridge University Press, 2004.

TARDE, Gabriel. "Monadologia e sociologia”. In Monadologia e sociologia e outros ensaios. São Paulo: Cosac Naify. [Cd] 2006 [1880]. 


\section{Referências Fonográficas:}

Bahia fantástica - 2o disco solo de Rodrigo Campos, lançado em 2012. Gravadora YB.

Efêmera - 1 disco solo de Tulipa Ruiz, lançado em 2010. Gravadora YB.

Longe de onde - 2º disco solo de Karina Buhr, lançado em 2011. Gravadora Coqueiro Verde.

Metal-Metal - 2o disco da banda Metá-Metá, lançado em 2012. Selo Desmonta. Nó na orelha - 1ํㅡㄹ disco solo de Criolo, lançado em 2011. Gravadora Oloko Records.

Tatá Aeroplano - 1ํo disco solo de Tatá Aeroplano, lançado em 2012. Independente.

autor Paulo Menotti Del Picchia

Doutorando em Antropologia Social pelo Programa de Pós-Graduação em Antropologia Social (PPGAS) da Universidade de São Paulo (USP). Músico, produtor musical e compositor.

Recebido em 15/05/2015 Aceito para publicaçáo em 15/05/2015 